\title{
A new paradigm for health research funding
}

$\mathrm{D}$ ramatic changes in health research strategies driven by shifts in technology and government policy are turning Canada's long-standing research funding system into "a burning platform," a panel of research leaders debated at the recent Canadian Science Policy Conference in Toronto, Ontario.

As a new research funding system emerges from the ashes of the old one, scientific survival will depend on a new skill set based on collaboration, communication and public interaction, the panellists agreed.

In Canada, targeted research is increasingly supplanting basic research investments. This has been attributed to government pressure on scientists to deliver economic benefits and declining support for research from pharmaceutical companies. "Many people argue we should be concentrating more on applying what we know," said Christine Williams, vice-president of research for the Canadian Cancer Society Research Institute.

While money flows toward applied research, "there's a push towards team science and big data, and one has to ask how easy that is for small research organizations," said Williams. The solution for these groups, she argued, is to focus on forging collaborations and promoting flexibility — two core elements adopted in a recent overhaul of the Canadian Cancer Society's research portfolio.

For researchers, success in finding funding now depends more on their communication skills, Williams suggested. "There is increasing emphasis on accountability and impacts, and we're asking researchers to do much more reporting," she explained. Cancer researchers, for example, are often required to explain how their research will directly impact cancer control.

"The issue becomes whether all scientists should be able to articulate the health impacts of their research," said Williams.

Indeed, scientific survival seems to depend more than ever on researchers' ability to collaborate and communicate, according to Peter Goodhand, executive director of the global alliance for sharing of genomic and clinical data at the Ontario Institute for Cancer Research. "Individual researchers and small teams are increasingly challenged," he noted.

As demand increases to provide open access to data sources, health researchers must also come to terms with more public exposure. "As the data comes forward, it changes the way science will be done," explained Goodhand. "We're seeing a democratization of science and growing engagement of nonscientists in science."

Panellists at the session ("Research Funding — new paradigms for a broken system?") also expressed concern over changes made by the Canadian Institutes for Health Research (CIHR) to streamline funding applications and peer review processes while scrapping traditional committee structures.

"Rapid wholesale change is risky," warned Goodhand. "It's good to be flexible."

Jane Aubin, vice-president for research and knowledge translation at CIHR, acknowledged that the research environment may be evolving faster than researchers can adapt. "A lot of researchers don't quite embrace it," she said.

Reforms to grant review processes are indeed a sensitive issue, said Phil Hieter, a professor of molecular genetics at the University of British Columbia. "Now, more than ever, our ability to rank grant applications and find the best science is important. The quality of peer review has never been more important than it is now. You can't make mistakes."

Overall, the future of health research funding in Canada is "a tremendous concern," said Hieter. With research funding from CIHR flatlined since 2008, "we're in a situation where we have a great car and great drivers but not enough fuel." - Paul Christopher Webster, Toronto, Ont.

CMAJ 2014. DOI:10.1503/cmaj.109-4669 